\title{
Breast tall cell carcinoma with reversed polarity with an unusual molecular profile
}

\author{
Kaitlyn J Nielson*1, Edgar G. Fischer ${ }^{1}$, Jacklyn Nemunaitis ${ }^{2}$, Sangeetha Prabhakaran ${ }^{3}$, Nadja K. Falk ${ }^{1}$ \\ ${ }^{1}$ Department of Pathology, University of New Mexico, Albuquerque, New Mexico, USA \\ ${ }^{2}$ Department of Internal Medicine, Division of Hematology/Oncology, University of New Mexico, Albuquerque, New Mexico, \\ USA \\ ${ }^{3}$ Department of Surgery, Division of Surgical Oncology, University of New Mexico, Albuquerque, New Mexico, USA
}

Received: September 22, 2020

DOI: $10.5430 /$ crcp.v $7 \mathrm{n} 1 \mathrm{p} 46$
Accepted: December 14, 2020 Online Published: December 27, 2020

URL: https://doi.org/10.5430/crcp.v7n1p46

\begin{abstract}
Breast tall cell carcinoma with reversed polarity (TCCRP) is rare and previously referred to as solid papillary carcinoma with reverse polarity. This low grade tumor commonly exhibits IDH2 p.Arg 172 mutation, however is not completely understood at the molecular level. We present a case of TCCRP in a 55 year old woman with a $0.7 \mathrm{~cm}$ left breast mass. A core biopsy was performed with immunohistochemistry. Lumpectomy and sentinel lymph node biopsy were completed two months later. MammaPrint ${ }^{\circledR}$ and BluePrint ${ }^{\circledR}$ gene expression profilers were performed on an excision block. Microscopically, the tumor was composed of circumscribed nests of columnar cells, with focal papillary architecture. Tumor cells had apically located nuclei with grooves and rare inclusions. Tumor cells were positive for CK5, IDH1/2, and calretinin, and myoepithelial cells were absent. BluePrint ${ }^{\circledR}$ subtyped the tumor as basaloid. MammaPrint ${ }^{R}$ classified the tumor as high risk for metastasis. TCCRP presents a diagnostic challenge. Although these rare breast carcinomas are generally reported to have an indolent clinical course, molecular analysis by gene expression profiling classified this tumor as high risk of recurrence with a basaloid type. Therefore, molecular analysis of this tumor may lead to conflicting data regarding prognosis and treatment considerations. Clinicians and patients should weigh published data and individual prognostic information for treatment planning. Our patient and clinical team opted for radiation without chemotherapy. More cases of TCCRP need to be studied to better understand its molecular profile.
\end{abstract}

Key Words: Breast tall cell carcinoma with reversed polarity, Molecular

\section{INTRODUCTION}

Breast cancer is the most commonly diagnosed malignancy in females, with over 250,000 new cases diagnosed in the United States annually. ${ }^{[1,2]}$ The most common diagnoses are invasive ductal carcinoma (70\%-75\%) and invasive lobular carcinoma (5\%-15\%). Papillary-type breast carcinomas represent approximately $1 \%$ of all breast cancer diagnoses. ${ }^{[3,4]}$ Breast tall cell carcinoma with reversed polarity (TCCRP) was described originally by Eusebi in 2003 in a five case series. ${ }^{[5]}$ In this report, Eusebi et al. rendered the first description of a breast tumor having histologic features similar to the tall cell variant of papillary thyroid carcinoma, composed of nests of eosinophilic cells in a papillary pattern with nuclear grooves and pseudo-inclusions. None of the patients described in this case series had a thyroid tumor, and in four of the cases, immunohistochemistry for thyroglobuStates. 
lin and TTF-1 was negative. Molecular studies determined none of the cases carried RET mutations that are associated with papillary thyroid carcinomas. Eusebi et al. therefore concluded that breast tumors mimicking this variant of papillary thyroid carcinoma should be included in the differential diagnoses for difficult papillary breast specimens to avoid clinical misdiagnosis.

Approximately 51 cases have been reported in literature, comprising less than 1 percent of annual breast cancer diagnoses. Following Eusebi et al., Camaselle-Teijeiro et al. (2006) described an additional case of this breast tumor with positive lymph node metastasis at the time of presentation. ${ }^{[6]}$ Follow-up for this patient revealed metastasis to the parietal bone at 32 months, making this the first report of aggressive disease. Additionally, testing for BRAF mutations associated with papillary thyroid carcinoma was negative.

From 2007-2015, seven additional cases of the breast tumor resembling the tall cell variant of papillary thyroid carcinoma were reported all demonstrating similar clinical and histologic features. ${ }^{[7-10]}$ Tosi et al. reported an intramammary lymph node with metastatic disease at the time of presentation and considered the tumor a malignant entity. In their case report, Masood et al. (2012) first described changing the name of the entity from breast tumor resembling the tall cell variant of papillary thyroid carcinoma to tall cell variant of papillary breast carcinoma, reiterating the hypothesis that these are unrelated to papillary thyroid carcinoma on the molecular level, despite the morphologic resemblance. ${ }^{[9]}$

Chiang et al. (2016) reported thirteen cases of this entity, redefining the terminology further by classifying them as solid papillary carcinoma with reverse polarity. ${ }^{[11]}$ The authors noted similar morphologic features to the previously reported cases, including apically located nuclei. Additionally, ten out of thirteen tumors were found to have hotspot R172 IDH2 mutations. This is the first description of IDH2 mutations in breast tumors, and the authors concluded that detection of this mutation may serve as a diagnostic tool for this diagnosis. Following this report, Bhargava et al. (2017) described three cases of this entity, and utilized next-generation sequencing to continue to identify cases with IDH2 mutations ( 2 of 3$){ }^{[12]}$

In 2017, Foschini et al. reported thirteen cases of TCCRP, noting that two patients had metastases to one lymph node each, and one of the patients had local recurrence. ${ }^{[13]}$ The authors note that all patients were free of disease 11 years after surgery, most of which did not require further treatment, concluding a low malignant potential. Most recently, Alsadoun et al. (2018) reported nine cases and highlighted the unique morphology and expression of cytokeratin 5/6 and calretinin. ${ }^{[14]}$ Seven cases demonstrated IDH2 mutations.

As seen above, the diagnosis of TCCRP has been previously referred to under a number of other names, including solid papillary carcinoma with reverse polarity and breast tumor resembling the tall cell variant of papillary thyroid carcinoma. This discrete diagnosis is newly present in the 2019 World Health Organization Classification, Tumors of the Breast. ${ }^{[15]}$

While the cells may resemble the tall cell variant of papillary thyroid carcinoma morphologically, these tumors do not express thyroid markers, such as TTF-1 and thyroglobulin, lack common thyroid genetic alterations in BRAF and RET, and are found in individuals without thyroid neoplasms. ${ }^{[13,14]}$ Additionally, breast origin is supported by positive immunohistochemical staining for GCDFP-15, GATA-3, and mammaglobin.

This low grade tumor has been found to commonly exhibit IDH2 p.Arg 172 mutation, however is not completely understood at the molecular level. ${ }^{[11]}$ We present a case of TCCRP with associated unusual molecular profiling.

\section{CASE PRESEntation}

A 55-year old female presented with a suspicious left breast mass being followed by mammograms for 2 years. Diagnostic mammogram and ultrasound described the $0.7 \mathrm{~cm}$ hypoechoic mass with indeterminate borders as intermediately suspicious for malignancy (BIRADS 4b). A core biopsy was obtained, followed by lumpectomy and sentinel lymph node biopsy two months later. MammaPrint ${ }^{\circledR}$ and BluePrint ${ }^{\circledR}$

(Agendia Inc., Irvine, CA), gene expression profilers, were performed on a formalin-fixed paraffin embedded block of the excision.

\subsection{Pathologic findings}

Four needle biopsy cores were obtained from the left breast at the 7 o'clock position. Microscopically, the tumor was composed of circumscribed nests of columnar epithelial cells, with focal papillary architecture and fibrovascular cores containing foamy histiocytes (see Figure 1A). Tumor cells had apically located bland nuclei with grooves and rare inclusions, and abundant eosinophilic cytoplasm. Mitoses were rare. By immunohistochemistry, tumor cells were positive for cytokeratin 5 (CK5) and staining with p63, calponin, and smooth muscle myosin heavy chain showed a lack of myoepithelial cells (see Figure 2A and 2B). Rare scattered tumor cells showed low estrogen receptor (ER) positivity (5\% of tumor cells, weak staining, Figure 2C) and were negative for progesterone receptor (PR). IDH1/2 and calretinin immunohistochemical stains were positive (see Figure 2D). 


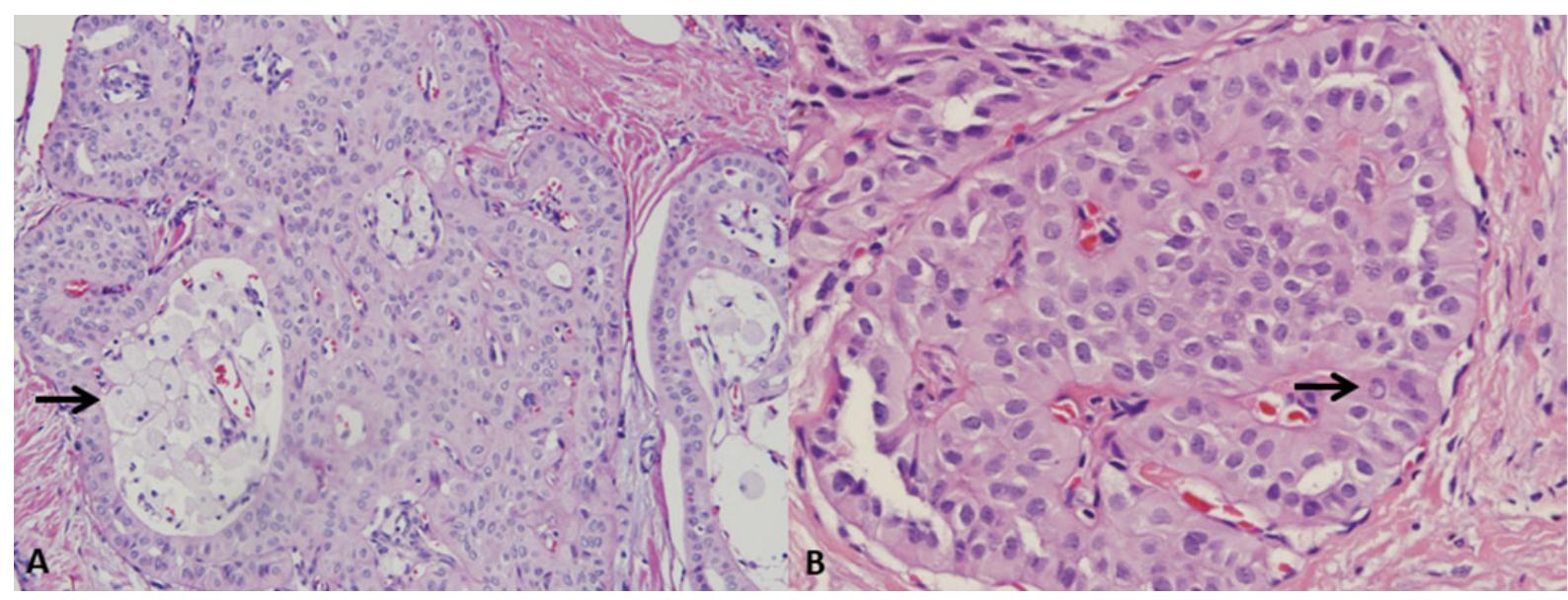

Figure 1. A. Histologically, the biopsy demonstrated circumscribed nests of columnar epithelial cells with apical nuclei with focal papillary architecture and foamy histiocytes (arrow) (biopsy, 200x). B. The excision specimen demonstrated similar morphology, including apical nuclei with grooves and occasional nuclear inclusions (arrow) (excision, 400x).

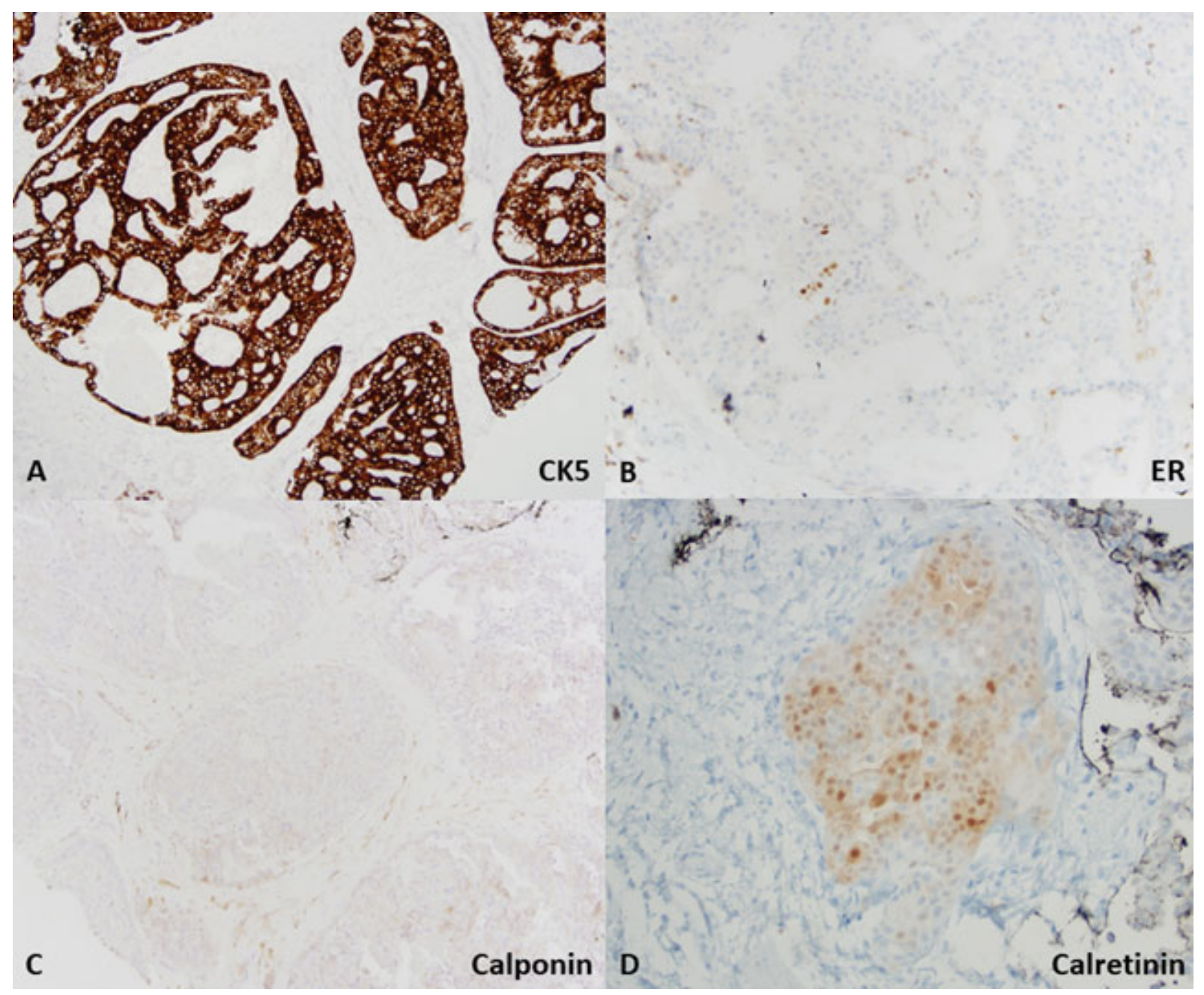

Figure 2. A. Tumor cells were positive for CK5 (biopsy, 100x). B. Tumor cells showed focal weak ER positivity (biopsy, 200x). C. Myoepithelial cells were absent by calponin (biopsy, 100x). D. Tumor cells were positive for calretinin (biopsy, $100 x)$. 
A SCOUT ${ }^{\circledR}$ localized excision was performed two months after the initial biopsy. The specimen was grossly fibrous and fatty, and sectioning revealed a $0.7 \mathrm{~cm}$ poorly-circumscribed, centrally papillary mass in the center of the specimen. The entire lesion was submitted for microscopic evaluation. Two sentinel lymph nodes were also evaluated. Similar histologic features were seen in the excision specimen, including nests of columnar cells with papillary architecture and grooved, apically located nuclei (see Figure 1B). Sentinel lymph node excision showed no metastatic carcinoma. The final pathologic stage (American Joint Committee on Cancer, 8th Edition) was pT1bNO(sn), clinically stage IA. ${ }^{[16]}$

Molecular profiling through BluePrint ${ }^{\circledR}$ and MammaPrint ${ }^{\circledR}$ was reported as basal-type and high-risk for metastasis and recurrence.

\section{Discussion}

The tumor's histologic features and molecular profile were consistent with TCCRP. Due to the unique nature of the diagnosis, the oncology team elected to pursue molecule profiling to better assess the need for chemotherapy. Blueprint ${ }^{\circledR}$ is an 80-gene micro-array based assay that classifies breast tumors into 3 categories: luminal-type, HER2-type, and basal-type. Basal-type breast carcinoma is also often referred to as triple negative breast cancer, as ER and PR, as well as HER-2, are negative in $75 \%$ of basal-type carcinomas. This type of carcinoma carries a poorer prognosis than luminal or HER2 type carcinomas. $^{[17]}$ MammaPrint ${ }^{\circledR}$ is a 70-gene micro-array based assay that is primarily used for patients with stage I and II breast cancer (with tumor size $\leq 5 \mathrm{~cm}$ and negative lymph nodes) in order to identify risk for distant metastasis or recurrence. ${ }^{[18]}$

Following gene expression profiling, BluePrint ${ }^{\circledR}$ subtyped the tumor as basal-type and MammaPrint ${ }^{\circledR}$ classified the tumor as high risk for metastasis and recurrence (average $29 \%$ risk of recurrence in 10 years). The profile also indicated a potential chemotherapy benefit. Despite the molecular findings, the clinical team elected to pursue radiation only, without chemotherapy, due to the generally indolent nature of the tumor, its small size, and lack of lymph node metastasis. The patient has done well post-operatively with post-radiation treatment and continues surveillance with the oncology team.

TCCRP presents a diagnostic challenge to surgical pathologists. The differential diagnosis includes solid papillary carcinoma and encapsulated papillary carcinoma. Solid papillary carcinoma histologically demonstrates nodules of round to spindle cells growing in a solid pattern, with inconspicuous fibrovascular cores. The tumor cells generally have granuPublished by Sciedu Press lar eosinophilic cytoplasm with mild to moderate cytologic atypia. ${ }^{[19]}$ The tumor cells are strongly and diffusely positive for ER, and are negative for CK5. ${ }^{[20]}$ The cells are also often positive for neuroendocrine markers including synaptophysin and chromogranin. Myoepithelial cells are absent within the nodule but may be present at the periphery. ${ }^{[19,21]}$ Encapsulated papillary carcinoma is characterized by wellcircumscribed nodules of neoplastic cells surrounded by a fibrous capsule, demonstrating a papillary growth pattern within the nodules with delicate fibrovascular cores. Tumor cells have low to intermediate grade nuclei and are positive for ER. ${ }^{[22]}$ Myoepithelial cells are usually absent both within and at the periphery of the lesion. ${ }^{[23]}$

Unlike these papillary carcinomas, most cases of TCCRP are ER, PR, and HER2 negative, or may show focal weak hormone receptor expression without HER2 positivity, as in this case. In TCCRP, myoepithelial cells are absent within the tumor and at the periphery. The lack of myoepithelial cells does not help distinguish TCCRP from solid papillary carcinoma or encapsulated papillary carcinoma; however, TCCRP does strongly express CK5, whereas solid papillary carcinoma and encapsulated papillary carcinoma do not express CK5. ${ }^{[12]}$ TCCRP cells also uniquely stain positive for calretinin.

At the genetic level, TCCRP has been characterized by IDH2 p.Arg 172 hotspot mutations. While IDH2 mutations are found in other malignancies, such as gliomas and acute myeloid leukemia, they are exceedingly rare in breast carcinomas other than TCCRP. This mutation has also been correlated with immunohistochemistry by positive staining for IDH1/2 mutant antibody. Alterations in PIK3CA have also been identified, but may also been seen in other breast carcinomas. ${ }^{[14,24]}$ These findings in TCCRP are still relatively recent and its unique molecular profile is an area requiring further study.

\section{Conclusion}

Although these rare breast carcinoma are generally reported to have an indolent clinical course, molecular analysis by gene expression profiling in this case was reported as high risk of recurrence (MammaPrint ${ }^{\circledR}$ ) with a basaloid type (BluePrint ${ }^{\circledR}$ ). Therefore, molecular analysis of this rare tumor subtype may lead to conflicting data with regards to prognosis and treatment considerations, and the clinical team and patient need to weigh all published data and individual prognostic information available for treatment planning. More cases of TCCRP need to be studied to better understand its molecular profile. 


\section{ACKNOWLEDGements}

The biopsy block and slides were sent for consultation (Dr. Stuart Schnitt, Harvard/Brigham and Women's Hospital where immunohistochemistry for calretinin and IDH1/2 was performed).

\section{CONFLicts OF InTEREST Disclosure}

The authors declare that they have no competing interests.

\section{REFERENCES}

[1] Miller KD, Nogueira L, Mariotto AB, et al. Cancer treatment and survivorship statistics. CA Cancer J Clin. 2019; 69(5): 363-385. PMid:31184787. https://doi.org/10.3322/caac. 21565

[2] Rakha EA, Allison KH, Ellis IO, et al. WHO Classification of Tumors Series, Breast tumours. 5th ed. France: Lyon: International Agency for Research on Cancer. Epithelial tumors of the breast, Invasive breast carcinoma: general overview. 2019. p. 82-101.

[3] Schnitt SJ, Collins LC. Biopsy Interpretation of the Breast. 3rd ed. Philadelphia, PA: Wolters Kluwer; 2018.

[4] Li C, Uribe D, Daling J. Clinical characteristics of different histologic types of breast cancer. Br J Cancer. 2005; 93(9): 1046-1052 PMid:16175185. https://doi.org/10.1038/sj.bjc.6602787

[5] Eusebi V, Damiani S, Ellis IO, et al. Breast tumor resembling the tall cell variant of papillary thyroid carcinoma: report of 5 cases. Am J Surg Pathol. 2003; 27(8): 1114-1118. PMid:12883243. https://doi.org/10.1097/00000478-200308000-00008

[6] Camaselle-Teireiro J, Abdulkader I, Barreiro-Morandeira F, et al Breast tumor resembling the tall cell variant of papillary thyroid carcinoma: a case report. Int J Surg Pathol. 2006; 14(1): 79-84. PMid:16501842. https://doi.org/10.1177/10668969060140 0116

[7] Tosi AL, Ragazzi M, Asioli S, et al. Breast tumor resembling the tall cell variant of papillary thyroid carcinoma: report of 4 cases with evidence of malignant potential. Int J Surg Pathol. 2007; 15(1): 14-19. PMid:17172492. https://doi.org/10.1177/10668969 06295689

[8] Chang SY, Fleiszer DM, Mesurolle B, et al. Breast tumor resembling tall cell variant of papillary thyroid carcinoma. Breast J. 2009; 15(5): 531-535. PMid:19594763. https://doi.org/10.1111/j.1524 $-4741.2009 .00773 . x$

[9] Masood S, Davis C, Kubik MJ. Changing the term "breast tumor resembling the tall cell variant of papillary thyroid carcinoma" to "tall cell variant of papillary breast carcinoma". Adv Anat Pathol. 2012; 19(2): 108-110. PMid:22313838. https://doi.org/10.1 097/PAP. 0b013e318249d090

[10] Colella R, Guerriero A, Giansanti M, et al. An additional case of breast tumor resembling the tall cell variant of papillary thyroid carcinoma. Int J Surg Pathol. 2015; 23(3): 217-220. PMid:24868004. https://doi.org/10.1177/1066896914536222

[11] Chiang S, Weigelt B, Wen H, et al. IDH2 Mutations Define a Unique Subtype of Breast Cancer with Altered Nuclear Polarity. Cancer Res. 2016; 76(24): 7118-7129. PMid:27913435. https: //doi.org/10.1158/0008-5472.CAN-16-0298

[12] Bhargava R, Florea AV, Pelmus M, et al. Breast tumor resembling tall cell variant of papillary thyroid carcinoma. Am J Clin Pathol. 2017; 147(4): 399-410. PMid:28375433. https://doi.org/10.1093/ ajcp/aqx016

[13] Foschini MP, Asioli S, Foreid S, et al. Solid papillary breast carcinomas resembling the tall cell variant of papillary thyroid neoplasms: A unique invasive tumor with indolent behavior. Am J Surg Pathol. 2017; 41(7): 887-895. PMid:28418993. https://doi.org/10.1 097/PAS.0000000000000853
[14] Alsadoun N, MacGrogan G, Truntzer C, et al. Solid Papillary Carcinoma With Reverse Polarity of the Breast Harbors Specific Morphologic, Immunohistochemical and Molecular Profile in Comparison With Other Benign or Malignant Papillary Lesions of the Breast: A Comparative Study of 9 Additional Cases. Mod Path. 2018; 31(9):1367-1380. PMid:29785016. https ://doi.org/10.1038/ s41379-018-0047-1

[15] Yang WT, Bu H, Foschini MP, et al. WHO Classification of Tumors Series, Breast tumours. 5th ed. France: Lyon: International Agency for Research on Cancer. Epithelial tumors of the breast, Tall cell carcinoma with reversed polarity. 2019. p. 153-154.

[16] Hortobagyi GN, Connolly JL, D’Orsi CJ, Eet al. AJCC, Cancer Staging Manual. 8th ed. Switzerland: Springer. Chapter 48, Breast. 2017 p. 589-636. https://doi.org/10.1007/978-3-319-40618-3 48

[17] Prat A, Adamo B, Cheang MC, et al. Molecular characterization of basal-like and non-basal-like triple negative breast cancer. Oncologist 2013; 18(2): 123-133. PMid:23404817. https://doi.org/10.1 634/theoncologist.2012-0397

[18] Cardoso F, van't Veer LJ, Bogaerts J, et al. 70-Gene Signature as an Aid to Treatment Decisions in Early-Stage Breast Cancer. N Engl J Med. 2016; 375(8): 715-729. PMid:27557300. https : //doi.org/10.1056/NEJMoa1602253

[19] Nassar H, Qureshi H, Volkanadsay N, et al. Clinicopathologic analysis of solid papillary carcinoma of the breast and associated invasive carcinomas. Am J Surg Pathol. 2006; 30(4): 501-507. PMid:16625097. https://doi.org/10.1097/00000478-20060 4000-00011

[20] Rabban JT, Koerner FC, Lerwill MF. Solid papillary ductal carcinoma in situ versus usual ductal hyperplasia in the breast: a potentially difficult distinction resolved by cytokeratin 5/6. Hum Pathol. 2006; 37(7): 787-793. PMid:16784976. https://doi.org/10.1016/j . humpath.2006.02.016

[21] Guo S, Wang Y, Rohr J, et al. Solid papillary carcinoma of the breast: a special entity needs to be distinguished from conventional invasive carcinoma avoiding over-treatment. Breast. 2016; 26: 67-72. PMid:27017244. https://doi.org/10.1016/j.breast. 2015. 12.015

[22] Duprez R, Wilkerson PM, Lacroix-Triki M, et al. Immunophenotypic and genomic characterization of papillary carcinomas of the breast. J Pathol. 2012 Feb; 226(3): 421-441. PMid:22025283. https://doi.org/10.1002/path. 3032

[23] Hill CB, Yeh IT. Myoepithelial staining patterns of papillary breast lesions: from intraductal papillomas to invasive papillary carcinoma. Am J Clin Pathol. 2005; 123(1): 36-44. PMid:15762278. https://doi.org/10.1309/XG7TPQ16DMJAV8P1

[24] Lozada JR, Basili T, Pareja F, et al. Solid papillary breast carcinoma resembling the tall cell variant of papillary thyroid neoplasms (solid carcinomas with reverse polarity) harbor recurrent mutations affecting IDH2 and PIK3CA: a validation cohort. Histopathology. 2018; 73(2): 339-344. PMid:29603332. https ://doi .org/10.1111/hi s. 13522 